\title{
A New Approach to Charging of Electric Vehicles
}

\author{
Maranda Mefooz ${ }^{1}$, Lalitha Mitra ${ }^{2}$ \\ Shahjalal University of Science and Technology, EEE, Sylhet, Bangladesh ${ }^{1,2}$
}

\begin{abstract}
This paper proposes a new control method for charging management of Electric Vehicles (EVs). The goals of the proposed control method are to reduce EV integration challenges, such as over-currents and under-voltages, and also improve the power factor. The proposed method controls the charging rates of the chargers in the distribution systems using cooperative control in order to prevent the network from under-voltages and overcurrents. The proposed algorithm is tested on the IEEE 33-Node Test Feeder and the simulation studies are carried out using OpenDSS and MATLAB. The pros and cons of the proposed method are presented and compared to the other EV charging methods.
\end{abstract}

Keywords: Electric vehicle, Charging, Phasor Measurement Unit (PMU), Distributed Control.

\section{INTRODUCTION}

The connection of EVs without any management and control system leads to issues such as over-currents and under-voltages in distribution systems [1]. As [2] suggests, the chargers with adjustable charging rates along with sophisticated charging management methods provide solutions to the EV connection problems. According to communication requirements, charging management methods can be divided into two groups as: 1) centralized methods in that a control centre optimizes and manages EV charging based on the received data from EVs. 2) Decentralized methods in that EVs are managed without a control centre and the intelligence is dispersed throughout the network [3].

The centralized methods provide more optimum outcomes for EV charging management in comparison with decentralized methods. However, a complicated communication infrastructure and considerable computational capability is needed [4], [5]. Decentralized control methods provide self-organizability and scalability by low communications and computational requirements [6]. Thus, decentralized methods seems to be more advantageous for $\mathrm{EV}$ charging management in close future using the available communication infrastructures.

In [7], a decentralized method based on game theory is proposed for minimization of charging costs. However, the electrical constraints are not considered. In [8], a distributed method based on the Lagrangian decomposition is proposed for arrangement of $\mathrm{EV}$ charging patterns and also compensation of reactive power. However, this method needs a coordinator to find the optimal solution [9]. In [10], every EV sends their demand to the aggregator. Them, the aggregator calculates the optimum solution by means of convex relaxation method and sends the result to each EV in the system [11]. Then, each EV makes decision to charge or to be idle. In [12], the system operator controls the number of charging EVs and informs the EVs in the system through communications. In [13], a real-time decentralized algorithm is proposed for management of the contributions of local solar panels for charging the EVs. In [14], using Alternating Direction Method of Multipliers (ADMM), iteratively the most optimum solution for EV charging is found. However, a huge amount of data should be transferred and a capable communication infrastructure is required. In , a myopic method is proposed based on the present system conditions. Every single EV operates in either charging or idle mode according to the received data from the aggregator and its SOC to reduce the negative effects of EVs on load deviation. An experimental testbed is described in [15] where voltage and current measurements are sent to the aggregator by means of power line carriers (PLCs), a thorough definition about PLC systems is proposed in [16]. If any measurement passes a predefined threshold, the aggregator disconnects some of the EVs from the distribution system. In [17], a cooperative control-based method is proposed for minimization of voltage drops and also for balancing the demand and generation of distributed generations. In [2], a new method for EV charging is proposed that prevents the technical parameters of the power system from being violated and also reduces the charging costs using sparse and low cost communications. The method does not require price or load prediction, which makes it more applicable.

In this paper, we propose a decentralized charging management method for EVs. The proposed method calculated the optimal solution and then sends the charging rates to each EV. The EV controller then selects either charging, discharging, or idle operating mode. During the charging mode, the local controller adjusts the charging rates utilizing the distributed cooperative control to retain the voltages and currents in the normal condition. The paper is organized as follows: The problem is stated in Section 2. In Section 3 describes the proposed method. 


\section{ISO 3297:2007 Certified}

Vol. 5, Issue 3, March 2017

In Section 3, the case study and results are provided, the year, day $\mathrm{d}$ of the week and hour $\mathrm{h}$ of the day can be discussed, and compared. In Section 4, conclusion is calculated.

presented.

\section{PROPOSED METHOD}

\section{A. Problem Statement}

When each EV reaches the charging location, it is plugged in immediately and charged with a variable power. The electric motor used as propulsion in EV is usually of induction type or high-efficiency permanent-magnet type [18],[19]. If a large number of EVs are put into charge in a specific part of the power system, a large power demand is forced on the power network in peak hours of the day [20]. If a fault happens, we can use current limiters to protect EVs against overcurrent faults [21]. In smart grids, an EV control centre is provided to control the charging rates of EVs. When the network is overloaded, the centre prevents some EVs from being charged or let them charge at lower rate than their rated value. This helps shifting the peak load from highly loaded hours to lightly loaded hours, and consequently, makes the load profile smoother.

B. The Models for Loads and EVs

For evaluation of the effect of EVs charging on the network, the base load profile and EV charging profile are required to be found, and then, these two profiles must be added. The added profile will be used in load flow calculation and the proposed objective function. In this section at first a brief description of the base load is presented, and then a comprehensive model for $\mathrm{EV}$ charging is presented.

\section{Load Model}

In [8], the yearly peak load data for all the substations are given. In order to analyse the system, it is needed to have system data for hours of a day. In order to create base load profile, the test system from reliability test system-1996 (IEEE RTS-96) is deployed [8]. What is important about this test system is that it includes a load factor which defines the relationship between the average demand in a given interval and the peak demand in that interval. IEEE RTS-96 network topology and the load factors for weekly peak load in percent of annual peak, daily peak load in percent of weekly peak and hourly peak load in percent of daily peak are given in [13]. A research has been conducted to investigate the effect of the load of data centre on supply management of solar energy [22].

Thus, according to above explanations, base load profile for every hour, day and week of the year and for every feeder are calculated by the following equation:

$$
D(n, \mathrm{w}, \mathrm{d}, \mathrm{h})=\mathrm{LF}(\mathrm{w}) \times L F(\mathrm{~d}) \times L F(\mathrm{~h}) \times \mathrm{MD}(n)
$$

where $\mathrm{LF}(\mathrm{w}), \mathrm{LF}(\mathrm{d}), \mathrm{LF}(\mathrm{h})$ and $\mathrm{MD}(\mathrm{n})$ are load factor in week $\mathrm{w}$ of the year, load factor in day $\mathrm{d}$ of the week, load factor in day $\mathrm{d}$ of the week, and annual peak demand in feeder i. Using Eq. (1), demand at Feeder i, in week w of

\section{Probabilistic EV Charging Model}

In this section, the calculation of load profile produced by EV charging is made. Thus a mathematic probabilistic model for EV charging is developed.

According to [12] and [23] all EVs can be divided into 4 classes namely: micro car, economy car, mid-size car and light truck/SUV. Each EV class is represented by a probabilistic parameter. The number of EVs in each class is a random variable with mean of $\mathrm{Pen}^{(\mathrm{c})}$ which in each class is equal to $0.2,0.3,0.3$ and 0.2 , respectively. In order to determine every class EV number normal distribution is taken into account. Therefore, in each class, mean and standard deviation are written as follows:

$$
\begin{aligned}
& \mu^{(c)}=N_{P H E V} \times \operatorname{Pen}^{(c)} \\
& \sigma^{(c)}=\sqrt{\alpha_{p} \times \mu^{(c)}}
\end{aligned}
$$

In which $N_{P H E V}$ is equal to total $\mathrm{EV}$ number in the region and $\alpha_{\mathrm{p}}$ is equal to 0.01 [11].

The second parameter which is modelled is EV battery capacity $\left(\mathrm{C}_{\mathrm{Bat}}^{(\mathrm{c}, \mathrm{v})}\right)$. Based on [8], EVs have battery with normal distribution with mean and standard deviation values corresponding to Eq. (4) and (5).

$$
\begin{aligned}
& \mu_{C_{B a t}}^{(c)}=\frac{\left(\operatorname{Min}_{B a t}^{c}+\operatorname{Max}_{B a t}^{c}\right)}{2} \\
& \mu_{C_{B a t}}^{(c)}=\frac{\left(\operatorname{Min} C_{B a t}^{c}+\operatorname{Max} C_{B a t}^{c}\right)}{2}
\end{aligned}
$$

In which the values of $\operatorname{MinC}_{\mathrm{Bat}}^{\mathrm{c}}$ and $\mathrm{MaxC}_{\mathrm{Bat}}^{\mathrm{c}}$ are equal to $(8,17,10,19)$ and $(12,14,21,23)$ for four classes respectively [10].

Another important parameter in EV charge modelling is daily travelled distance $\left(\operatorname{Tr}_{\mathrm{d}}^{(\mathrm{v}, \mathrm{d})}\right)$ by each EV. According to [12] daily travelled distance distribution can be expressed as a normal distribution with mean value and standard deviation value of $\left(\sigma_{\mathrm{m}}=5 \mathrm{miles}=54 \mathrm{~km}\right)$. An important parameter related to daily traveled distance is grid energy required per $\mathrm{km}$ distance traveled $\left(\mathrm{E}_{\mathrm{k}}^{(\mathrm{c})}\right)$. According to [10], $\mathrm{E}_{\mathrm{k}}^{(\mathrm{c})}$ can be finely approximated to $0.19,0.2,0.22$, and 0.24 for four classes, respectively.

The next important parameter for EV charging in home, is the required grid energy $\left(\mathrm{E}_{\mathrm{G}}^{(\mathrm{v}, \mathrm{c}, \mathrm{d})}\right)$ and state of charge (SOC). When EVs leave and then return home, they may consume fuel or not, depending on how much distance they travel during the day. Moreover, in account for not taking any damage during the charging, it is assumed that EVs have an allowable SOC limit $10 \%$ and $80 \%$. Eq. (6), 


\section{ISO 3297:2007 Certified}

Vol. 5, Issue 3, March 2017

(7) shows relationship between SOC of arrival time and departure time with the fuel and the required grid energy.

$$
\begin{aligned}
& S O C_{a}{ }^{(\mathrm{v}, \mathrm{c}, \mathrm{d})}=S O C_{d}^{(\mathrm{v}, \mathrm{c}, \mathrm{d})}-\frac{\left(\operatorname{Tr}_{d}{ }^{(\mathrm{v}, \mathrm{d})} \times \mathrm{E}_{k}^{(\mathrm{c})}\right)}{C_{B a t}^{(\mathrm{v}, \mathrm{c})}}+F u e l_{p}^{(\mathrm{v}, \mathrm{c}, \mathrm{d})} \\
& S O C_{d}{ }^{(\mathrm{v}, \mathrm{c}, \mathrm{d}+1)}=S O C_{a}^{(\mathrm{v}, \mathrm{c}, \mathrm{d})}+\frac{E_{G}^{(\mathrm{v}, \mathrm{c}, \mathrm{d})}}{C_{B a t}^{(\mathrm{v}, \mathrm{c})}}
\end{aligned}
$$

Where $S O C_{a}{ }^{(\mathrm{v}, \mathrm{c}, \mathrm{d})}$ and $S O C_{d}^{(\mathrm{v}, \mathrm{c}, \mathrm{d})}$ are SOC of arrival time and SOC of departure time to home, respectively. Since it is assumed that vehicles charged fully at home in the previous day, $S O C_{d}^{(\mathrm{v}, \mathrm{c}, \mathrm{d})}$ is set to 0.8. Further, $F u e l_{p}^{(\mathrm{v}, \mathrm{c}, \mathrm{d})}$ denotes percent of the consumed fuel. The last probabilistic parameter which is considered in the modelling is the arrival and departure time of vehicles to home. According to [15], the arrival and departure time of vehicles are as Table I.

In unmanaged charging modelling of EVs, it is assumed that vehicles are plugged-in immediately, when they arrive home, and are charged with constant $3 \mathrm{~kW}$ power [13]. As a result, vehicles are charged as much as possible depending on their battery capacities and arrival times to home. Therefore, in order to obtain load profile of EV charging, load profile of every vehicle should be summed to each other. It must be noted that the influence disruptive shocks and external forces on the performance of the system is considerable, and recently using phasor measurement units (PMU), the disturbances in power networks (i. e., disruptive events) are reported[24]-[26].

\section{E. Objective Function}

In order to manage charging of EVs in a smart way, their received power must be controlled in a smart way. From theoretical point of view, the best case happens when power is controlled instantaneously. However, because of voluminous computer data it is assumed that control time interval is $15 \mathrm{~min}$. For improving voltage profile and network power factor, the objective function is chosen such that the difference between square power factor and ideal power factor (equal to unity) is minimized. The objective function is expressed in Eq. (8).

$$
\min z=\sum_{i=1}^{32} \sum_{t=1}^{96} \sum_{d=1}^{7}(\cos \phi(\mathrm{d}, \mathrm{t}, \mathrm{i})-1)
$$

Some limits of the optimization as constraints, are represented by Eq. (9)-(12). Also slack and other substation active and reactive powers limitations should be considered.

$$
\begin{aligned}
& \frac{\left[P_{\text {slack }}(t)-P_{1}(\mathrm{t})\right]}{1000}=\sum_{j=1}^{33}\left|v_{1}(t)\right| \times\left|v_{j}(t)\right| \times\left|y_{1 j}\right| \\
& \times \cos \left[\theta_{1}(t)-\theta_{j}(t)-\varphi_{1 j}\right], \forall t=1,2, \ldots, 96
\end{aligned}
$$

Table I Statistical data related to EVs.

\begin{tabular}{ccccc}
\hline & \multicolumn{2}{c}{ Arrival Time (hour) } & \multicolumn{2}{c}{ Departure Time (hour) } \\
Parameter & weekday & weekend & weekday & weekend \\
Mean $\left(\mu_{\mathrm{T}}^{(\mathrm{p})}\right)$ & 18 & 15 & 7 & 9 \\
Variance & 3 & 6 & 3 & 6 \\
\hline
\end{tabular}

$\frac{\left[Q_{\text {slack }}(t)-Q_{1}(\mathrm{t})\right]}{1000}=\sum_{j=1}^{33}\left|v_{1}(t)\right| \times\left|v_{j}(t)\right| \times\left|y_{1 j}\right|$

$\times \sin \left[\theta_{1}(t)-\theta_{j}(t)-\varphi_{1 j}\right], \forall t=1,2, \ldots, 96$

$\frac{-\left[P_{i}(t)+P_{\text {PHEV }}(\mathrm{t})\right]}{1000}=\sum_{j=1}^{33}\left|v_{i}(t)\right| \times\left|v_{j}(t)\right| \times\left|y_{i j}\right|$
$\times \cos \left[\theta_{i}(t)-\theta_{j}(t)-\varphi_{i j}\right], \forall t=1,2, \ldots, 96, \forall i=2, \ldots, 33$

$\frac{-Q_{i}(t)}{1000}=\sum_{j=1}^{33}\left|v_{i}(t)\right| \times\left|v_{j}(t)\right| \times\left|y_{i j}\right| \times \sin$

$\left[\theta_{i}(t)-\theta_{j}(t)-\varphi_{i j}\right], \forall t=1,2, \ldots, 14400, \forall i=2, \ldots, 33$

where, $\left|v_{i}(t)\right|, \theta_{i}(t)$ are the magnitude and phasor angle of voltage, respectively. $P_{\text {slack }}(t)$ and $Q_{\text {slack }}(t)$ are the active and reactive power of slack bus. Moreover, $P_{i}(t)$ and $Q_{i}(t)$ are thedemand active and reactive power of buses, respectively. In Eq. (11), $\mathrm{P}_{\mathrm{PHEV}_{\mathrm{i}}}(\mathrm{t})$ is power demand of EVs.Eq. (13)-(16) are substation voltage magnitude and angle limits in slack and other substations. They are also considered as the other constraints.

$v_{1}(t)=1, \forall t=1,2, \ldots, 96$

$\theta_{1}(t)=1, \forall t=1,2, \ldots, 96$

$0.95 \leq v_{i}(t) \leq 1.05, \forall t=1,2, \ldots, 96, \forall i=2, \ldots, 33$

$-3.14 \leq \theta_{i}(t) \leq 3.14, \forall t=1,2, \ldots, 96, \forall i=2, \ldots, 33$

(8) The next two equations are constraints that form EV managed charging curve and required grid energy. In (17), $N_{i}$ is equal to the total vehicles on bus $\mathrm{i}$, and is distributed on each bus with respect to annual peak load. The next two equations are constraints which determine SOC of arrival and departure time.

$P_{P H E V i}(\mathrm{t})=\sum_{k=1}^{N_{i}} P_{P H E V c}(\mathrm{k}, \mathrm{t})$,
$\forall i=2, \ldots, 33, \forall t=1,2, \ldots, 96$ 


\section{ISO 3297:2007 Certified}

Vol. 5, Issue 3, March 2017

$$
E_{G}^{(\mathrm{v}, \mathrm{c}, \mathrm{d})}=\sum_{t=A_{T}(\mathrm{~d})}^{D_{T}(\mathrm{~d}+1)} P_{P H E V c}(v, d, t) \times 0.25, \forall t=1,2, \ldots, 96
$$

In (17), $N_{i}$ is equal to the total vehicles on bus i, and is distributed on each bus with respect to annual peak load. The next two equations are constraints which determine SOC of arrival and departure time.

$$
\begin{gathered}
S O C_{a}^{(\mathrm{v}, \mathrm{c}, \mathrm{d})}=S O C_{d}^{(\mathrm{v}, \mathrm{c}, \mathrm{d})}-\frac{\left(\mathrm{Tr}_{d}^{(\mathrm{v}, \mathrm{d})} \times \mathrm{E}_{k}^{(\mathrm{c})}\right)}{C_{B a t}^{(\mathrm{v}, \mathrm{c})}}+F u e l_{p}^{(\mathrm{v}, \mathrm{c}, \mathrm{d})} \\
S O C_{d}^{(\mathrm{v}, \mathrm{c}, \mathrm{d}+1)}=S O C_{a}^{(\mathrm{v}, \mathrm{c}, \mathrm{d})}+\frac{E_{G}^{(\mathrm{v}, \mathrm{c}, \mathrm{d})}}{C_{B a t}^{(\mathrm{v}, \mathrm{c})}}
\end{gathered}
$$

Finally, (21) and (22) specify limits of SOC of arrival and departure times, respectively.

$$
\begin{aligned}
& 0.1 \leq \operatorname{SOC}_{a}{ }^{(\mathrm{v}, \mathrm{c}, \mathrm{d})} \leq 0.8 \\
& \operatorname{SOC}_{d}{ }^{(\mathrm{v}, \mathrm{c}, \mathrm{d})}=0.8
\end{aligned}
$$

\section{III.TEST CASE AND SIMULATION RESULTS}

In this section, simulation results before and after charge management will be presented. At first, simulation results before smart charging has been presented. Next, simulation results after managed charging has been presented. The simulation results have been presented for a typical weekday in winter and with penetration factor of $25 \%, 50 \%, 75 \%$, and $100 \%$ in a typical bus. All simulations have been conducted via MATLAB software. The test network is a radial 33 substations IEEE test network with $12.66 \mathrm{kV}$ nominal voltage [7]. Fig.1 shows the single line diagram of 33 substations distributed network.

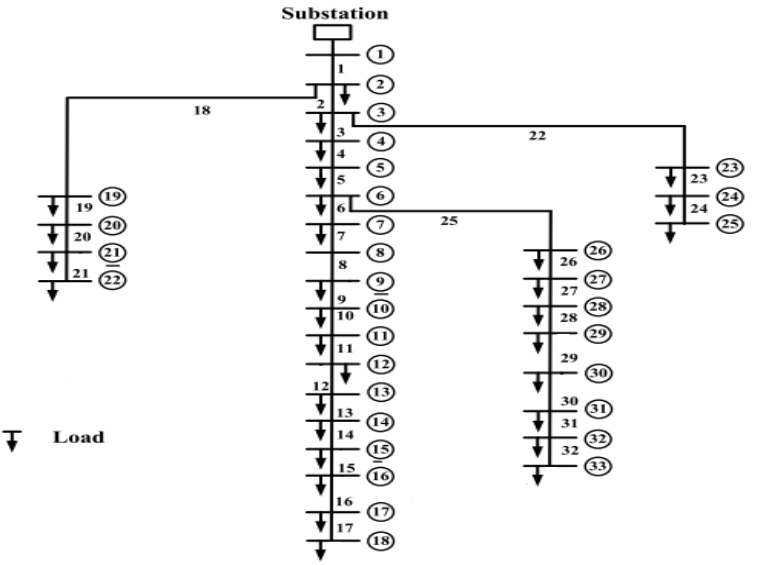

Fig. 1. Single line diagram of the 33-Substation distributed network

F. Unmanaged EV Charging

In unmanaged charging, as it described earlier, vehicles are plugged in just right after they come home. As a result, vehicles are charged to their maximum capacities. Fig. 2 shows the outcomes resulting from unmanaged charging of EVs.

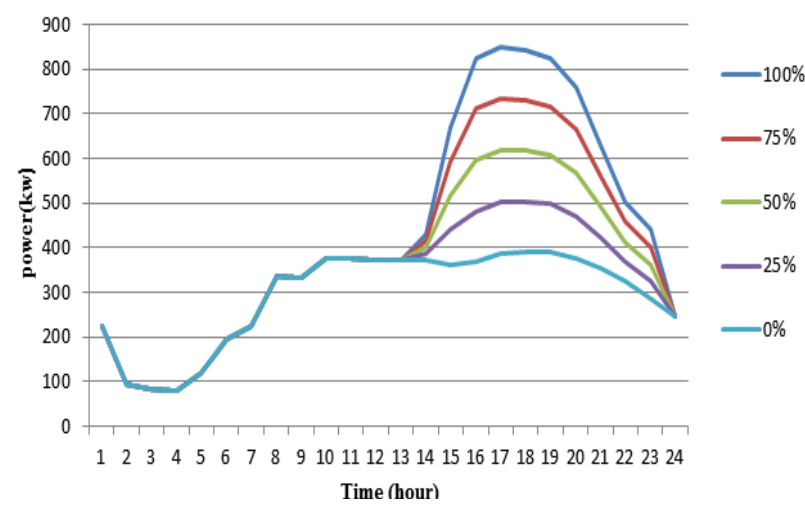

Fig. 2. Load profile following unmanaged charging.

As it can be seen from Fig. 2, EVs are charged approximately between 13 o'clock and 24 o'clock, and most of vehicles are charging about 18 o'clock. Therefore, there is a peak twice amount of normal peak at this period of time.

Fig. 3 illustrates the voltage profile before the smart charging. As it can be observe from the Fig, between 13 o'clock and 24 o'clock that PHEVs are plugged in, voltage drops from the normal situation, and the more penetration level increases, the more voltage drops. Also, it can be seen that voltage drops down to $0.968 \mathrm{pu}$ In other hours of the day that no EVs are charged, the voltage profile has not changed. Moreover, as penetration level increases, the voltage profile lost its flatness.

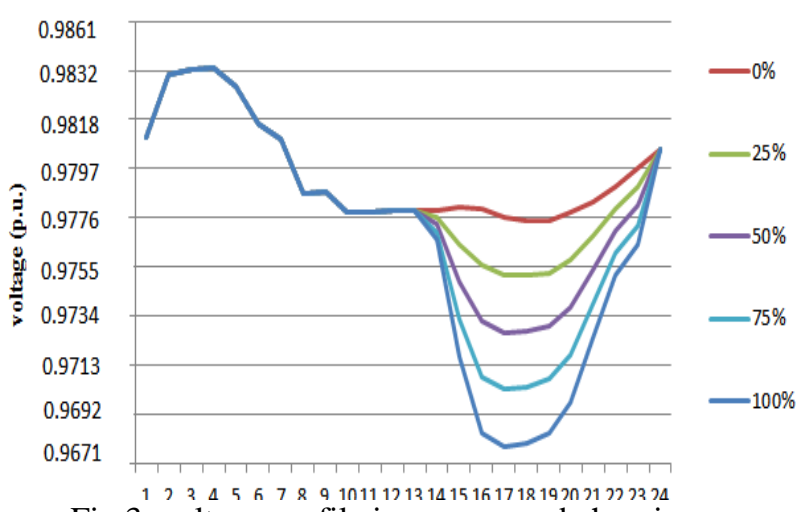

Fig 3. voltage profile in unmanaged charging.

The next curve is power factor curve when EVs are charged in unmanaged method. This curve is depicted in Fig 4. As it can be perceived, at the beginning hours of the day, because the ratio of active power to reactive power has a low amount, the power factor drops to even 0.75 . However, at the next hours, this amount reaches to above of 0.9 , and in the period of hours that vehicles are charged, this amount increases, due to increase in the active power drawn from the network. 


\section{ISO 3297:2007 Certified}

Vol. 5, Issue 3, March 2017
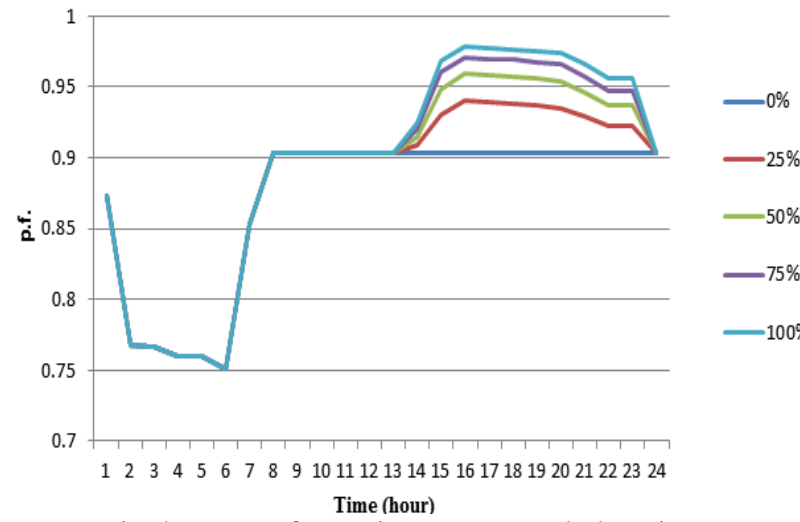

Fig 4. Power factor in unmanaged charging.

G. EV Charging using the Proposed Method

Fig. 5 illustrates voltage profile using the proposed EV charging method. As it is noticed in this Fig, instead of being charged in peak load hours, using charge management model, vehicles charge interval is shifted to the lightly loaded hours.

As it is obvious from the Fig., in this case, load profiles are flatter than the previous case that demonstrates the effectiveness of smart charging.
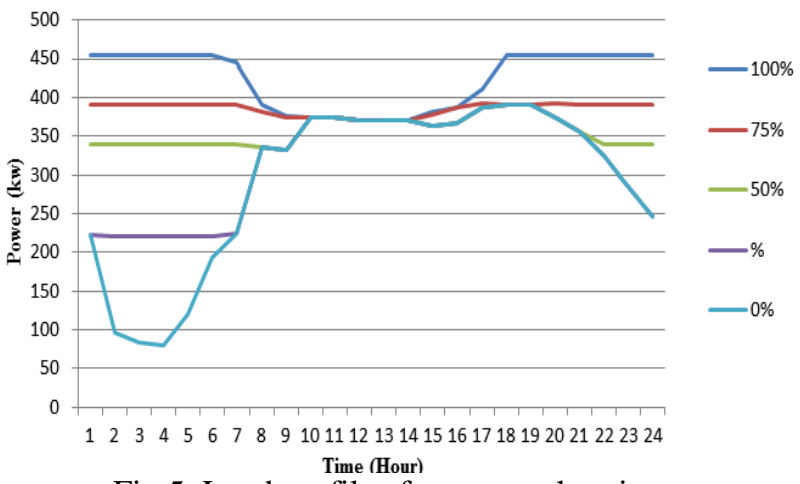

Fig 5. Load profile after smart charging.

Voltage profile after smart charging is depicted in Fig. 6. This Fig shows that voltage profile is smoother than the previous case, and also in this case for penetration level of $100 \%$, voltage reaches to $0.976 \mathrm{pu}$ which is better than the unmanaged case which was about $0.968 \mathrm{pu}$. As a result, in this case, not only voltage is smoother, but the voltage is also place in the upper range. The last curve is power factor after vehicles charged in a smart way.

As it can be seen in Fig. 7 and in comparison to Fig 4, for different penetration levels, voltage becomes smoother, and in overall, for most of hours, power factor lays more than 0.9. The main difference considered in these two Figs is in beginning hours of the day. With smart charging, most of vehicles instead of charging in peak hours are charged in lightly loaded hours and consequently, in these hours with increase in drawn active power from the network, power factor increases.

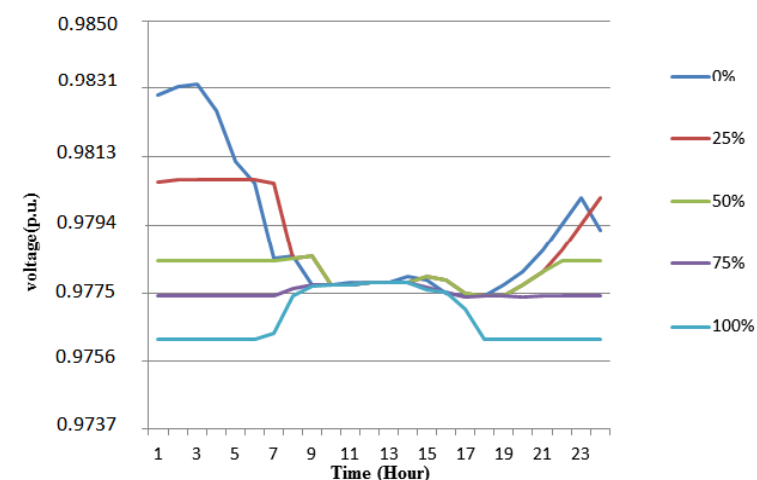

Fig 6. Voltage profile using the proposed method.

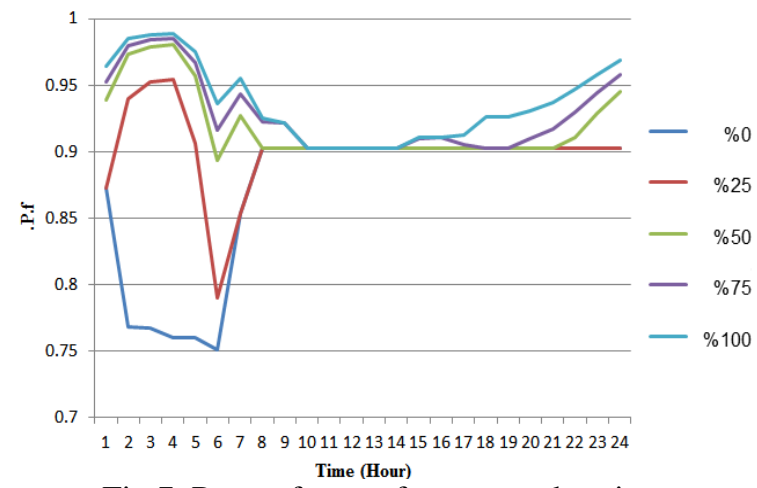

Fig 7. Power factor after smart charging.

\section{IV.CONCLUSION}

In this paper an objective function based on probabilistic model with taking account of fuel consumption has been developed to optimize the voltage profile and power factor in a distributed network. This paper employs a probabilistic model including parameters such as battery capacity, daily travelled distance and arrival time and departure time of EVs to and from home. The method has been applied to an IEEE test network. In order to control the received power by EVs and improve the voltage profile and power factor, an EV control canter in a smart grid has been utilized. The simulation results have validated the proposed model.

\section{REFERENCES}

[1] S. Han, S. Han, Kaoru Sezaki, "Development of an optimal vehicleto-grid aggregator for frequency regulation," IEEE Trans. Smart Grid,vol. 1,pp. 65-72, 2010.

[2] R. Jalilzadeh Hamidi and H. Livani, "Myopic real-time decentralized charging management of plug-inhybrid electric vehicles," EPSR, vol. 143, pp. 522-532, 2017.

[3] K. Clement-Nyns, E. Haesen, J. Driesen, The impact of charging plug-in hybridelectric vehicles on a residential distribution grid, IEEE Trans. Power systems,pp. 371-380, 2010.

[4] Chorzepa, Mi G., and Yaghoobi A. "Innovative meshless computational method for the analysis of fiber-reinforced concrete (FRC) structures," Geotechnical and Structural Engineering Congress, 2016

[5] A. Yaghoobi, "Implementation of non-linear finite element usingobject-oriented design patterns" Journal of Mechanical Engineering and Technology (JMET), 2012 


\section{International Journal of Innovative Research in Electrical, Electronics, Instrumentation and Control Engineering}

\section{ISO 3297:2007 Certified}

Vol. 5, Issue 3, March 2017

[6] J. A. Pec, as Lopes, C.L. Moreira, A.G. Madureira, "Defining control strategies formicrogrids islanded operation," IEEE Trans. Power Syst. Vol. 21, pp. 916-924, 2006.

[7] Z. Ma, D.S. Callaway, I.A. Hiskens, "Decentralized charging control of largepopulations of plug-in electric vehicles," IEEE Trans. Control Syst. Technol. vol. 21, no. 1, pp. 67-78, 2013.

[8] B. Jiang, Y. Fei, "Decentralized scheduling of PHEV on-street parking andcharging for smart grid reactive power compensation," ISGT, Shanghai, China, pp. 1-6, 2013.

[9] Sarfi, Vahid, Iman Niazazari, and Hanif Livani. "Multiobjective fireworks optimization framework for economic emission dispatch in microgrids" In North American Power Symposium (NAPS), pp. $1-6,2016$.

[10] C.K. Wen, J.C. Chen, J.H. Teng, P. Ting, Decentralized plug-in electric vehiclecharging selection algorithm in power systems, IEEE Trans. Smart Grid vol. 3, pp. 1779-1789, 2012.

[11] M. Masoomi, N. Shamsaei, X. Gao, S. M. Thompson, A. Elwany, L. Bian, N. Shamsaei, L. Bian, and A. Elwany, "Modeling, simulation and experimental validation of heat transfer during selective laser melting," in ASME 2015 International Mechanical Engineering Congress \& Exposition, 2015.

[12] K. Turitsyn, N. Sinitsyn, S. Backhaus, M. Chertkov, "Robustbroadcast-communication control of electric vehicle charging,"SmartGridComm, MD, USA, 2010, pp. 203-207.

[13] I. Harrabi, M. Maier, "Performance analysis of a real-time decentralized algorithm for coordinated PHEV charging at home and workplace with PV solar panel integration," PES GM, WA, USA, pp. 1-5, 2014.

[14] M.G. Vaya, G. Andersson, S. Boyd, "Decentralized control of plugin electricv under driving uncertainty," ISGT-Europe, Istanbul, Turkey, pp.1-6, 2014.

[15] T. Li, R. Cui, F. Franchetti, D. Ilic, "On-line decentralized charging of plug-inelectric vehicles in power systems," 2011 [Online]. Available: arXiv:1106.5063.

[16] R. Jalilzadeh Hamidi, S.H. Hosseinian, S.H.H. Sadeghi, and Z. Qu, "A novel approach to utilize plc to detect corroded and eroded segments of power transmission lines," IEEE Trans. Power Delivery, vol. 30, no. 2, pp. 746 - 754, 2015

[17] R. Mahmud, A. Nejadpak, R. Ahmadi, Cooperative Load Sharing in V2GApplication, EIT, IL, USA, pp. 451-456, 2015.

[18] SeyyedmahdiJafariShiadeh, Mohammad Ardebili, and Parvin Moamaei, "Three-dimensional finite-element-model investigation of axial-flux PM BLDC machines with similar pole and slot combination for electric vehicles", In: Proceedings of Power and Energy Conference, Illinois, pp. 1-4, 2015.

[19] S. M. Jafari-Shiadeh and M. Ardebili, "Analysis and comparison of axial-flux permanent-magnet brushless-DC machines with fractional-slot concentrated-windings", Proc. 4th Annual Int. Power Electron., Drive Syst., Technol. Conf., pp. 72-77, 2013.

[20] M. Masoomi, "Model development and load analysis of an offshore wind turbine," 2014.

[21] Sarfi, V., V. Hemmati, and M. M. Arabshahi. "Simulation of PTC devices as fault current limiters in power systems by finite element method"in High Voltage Engineering and Application (ICHVE), 2014 International Conference on, pp. 1-4. IEEE, 2014.

[22] M. Ghaisi Rad, M. Rahmani, P. Gharghabi, A. Zoghi, S.H. Hosseinian "Scheduling a wind hydro-pumped-storage unit considering the economical optimization," American Journal of Electrical and Electronic Engineering, vol. 5, no. 1, pp. 16-22, 2017.

[23] I. Niazazari, H.A. Abyaneh, M. J. Farah,F. Safaei, andH. Nafisi,"Voltage profile and power factor improvement in PHEV charging station using a probabilistic model and flywheel," In Electrical Power Distribution Networks (EPDC), 2014 19th Conference on pp. 100-105. May. 2014.

[24] P. Gharghabi, P. Dordizadeh, and K. Niayesh, "Impact of metal thickness and field-shaper on the time-variant processes during impulse electromagnetic forming in tubular geometries," Journal of the Korean Physical Society, vol. 59, no. 61, p. 3560-3566, 2011.

[25] PeymanDordizadeh B., PedramGharghabi, and KavehNiayesh. "Dynamic analysis of a fast-acting circuit breaker (Thompson) drive mechanism," Journal of the Korean Physical Society, vol. 59, no. 6 , pp. 3547-3554, 2011.
[26] I. Niazazari and H. Livani. "Disruptive event classification using pmu data in distribution networks," In 2017 IEEE PES General Meeting, Chicago, IL, Jul. 2017. 